\title{
Effects of treatment of anestrous dairy cows with gonadotropin-releasing hormone, prostaglandin, and progesterone
}

\author{
S. McDougall ${ }^{1}$ \\ Animal Health Centre, PO Box 21, Morrinsville, New Zealand, 3300
}

\begin{abstract}
Cows anestrous at the start of a seasonal breeding period have lesser probability of breeding, lesser conception rates, and a longer interval to conception than cycling herdmates. Historically, treatment included estradiol benzoate, which is no longer available. Consequently, alternative programs are required. Hence, a study was undertaken to assess new treatment regimens for these cows. The presence or absence of a corpus luteum was determined using ultrasonography in cows ( $\mathrm{n}=2,222$ from 12 herds) that were not detected in estrus by $9 \mathrm{~d}$ before the start of breeding. Cows were then randomly assigned to one of 4 treatments within each herd. Treatments were (1) $100 \mu \mathrm{g}$ of gonadorelin, followed $7 \mathrm{~d}$ later by $500 \mu \mathrm{g}$ of sodium cloprostenol, followed 54 to $56 \mathrm{~h}$ later by $100 \mu \mathrm{g}$ of gonadorelin, followed by fixed-time artificial insemination at 13 to $18 \mathrm{~h}$ after the final GnRH injection (Ovsynch); (2) as for (1) but with placement of an intravaginal progesterone (P4)-releasing insert between the initial $\mathrm{GnRH}$ and $\mathrm{PGF}_{2 \alpha}$ (Ovsynch-56+P4); (3) as for (2) but with the final $\mathrm{GnRH}$ treatment delayed until $71 \mathrm{~h}$ after $\mathrm{PGF}_{2 \alpha}$ and $\mathrm{P} 4$ insert removal with fixed-time artificial insemination 0 to $5 \mathrm{~h}$ after $\mathrm{GnRH}$ treatment and with insemination of those cows detected in estrus before the second GnRH injection (Cosynch-72+P4); and (4) untreated controls (control). Day 0 was defined as the day of the second GnRH injection. Milk samples were collected from 154 and 152 cows from the Ovsynch and Ovsynch-56+P4 treatments, respectively, at d 0, 7, and 14 for P4 concentration determination. This was to test the hypothesis that inclusion of $\mathrm{P} 4$ would result in a greater proportion of cows having normal luteal function after treatment in these 2 groups that differed only in the inclusion of $\mathrm{P} 4$ in the Ovsynch-56+P4 treatment. All treatments resulted in shorter intervals from first day of breeding to conception compared with the controls. The Ovsynch-56+P4 treatment resulted in start of breeding to conception intervals 3,6 , and
\end{abstract}

Received April 16, 2009.

Accepted January 4, 2010.

${ }^{1}$ Corresponding author: smcdoug@ahc.co.nz
$16 \mathrm{~d}$ shorter than those of Cosynch-72+P4, Ovsynch, or controls, respectively, and the positive effect of the Ovsynch-56+P 4 treatment occurred both in corpusluteum-positive and in corpus-luteum-negative cows. The Ovsynch-56+P4 treatment resulted in fewer short interestrus intervals than did Ovsynch (i.e., $<18$ d; 16 vs. $31 \%)$ and more cows with elevated $(>1 \mathrm{ng} / \mathrm{mL})$ milk P4 concentrations at $\mathrm{d} 7$ (88 vs. $74 \%)$ and $\mathrm{d} 14(80$ vs. $60 \%$ ). It was concluded that treatment of anestrous cows before the start of breeding resulted in earlier conception than no treatment but had no effect on the final pregnancy rate. The addition of $\mathrm{P} 4$ to the Ovsynch program resulted in earlier conception and in more cows with normal subsequent luteal-phase lengths.

Key words: anestrus, treatment, Ovsynch, progesterone

\section{INTRODUCTION}

Extended postpartum anovulation and anestrus are common, with approximately $20 \%$ of dairy cows anestrus by the start of breeding programs (Rhodes et al., 2003) or by $63 \mathrm{~d}$ after calving (Santos et al., 2004), and in another study, $28 \%$ of cows had not ovulated by the time of the first GnRH treatment of an Ovsynch program that commenced, on average, $66 \mathrm{~d}$ after calving (Stevenson et al., 2008). In seasonal breeding systems, fewer anestrous cows are detected in estrus during the first $3 \mathrm{wk}$ of the breeding period ( 55 vs. $96 \%$ ) and they have longer intervals to conception (37 vs. 22 d) than cows that have displayed estrus before the start of the seasonal breeding program (Macmillan, 2002). A metaanalysis found that prolonged anestrus was associated with an $18 \%$ decline in first-service conception rate, a 41-d-longer calving-to-conception interval, and a relative risk of conception overall of 0.68 (Fourichon et al., 2000). Under New Zealand management systems, between 10 and $30 \%$ of anestrous cows have a corpus luteum (CL). These CL-positive, anestrous cows have reduced pregnancy rates during the first $28 \mathrm{~d}$ of the breeding program (59 vs. $67 \%$ ) and have greater nonpregnancy rates at the end of the breeding period (10 vs. 4\%) compared with cows detected in estrus before the start of breeding (McDougall and Rhodes, 1999). 
Until the recent European Union ban on use of estradiol in food-producing animals, anestrous cows were commonly treated with intravaginal progesterone $(\mathbf{P} 4)$ for 7 to $8 \mathrm{~d}$ in combination with $2 \mathrm{mg}$ of estradiol benzoate (EB) at insert insertion and $1 \mathrm{mg}$ of EB $1 \mathrm{~d}$ after insert removal (McDougall and Compton, 2005). This protocol resulted in more cows pregnant in the first 4 wk of the breeding program (35 vs. 55\%) and reduced the interval from start of breeding to conception (40 vs. 25 d) for 384 treated compared with 388 untreated control cows (McDougall and Compton, 2005).

Estradiol benzoate was included in these protocols because it resulted in a greater proportion of cows exhibiting estrus after treatment with P4 (McDougall et al., 1992) compared with programs without EB. Injection of estradiol $17-\beta$ at the time of insertion of a P4 insert resulted in emergence of a new cohort of follicles in 3 to $6 \mathrm{~d}$ in all animals (Bo et al., 1995) and 38 of $45(84 \%)$ cows having a new follicle wave emergence 1 to $5 \mathrm{~d}$ after EB treatment (Souza et al., 2009), ensuring the presence of a growing follicle at the time of insemination. Failure to induce atresia or ovulation of the existing dominant follicle may result in development of persistent ovarian follicles (Sirois and Fortune, 1990; Savio et al., 1993) and reduced fertility (Mihm et al., 1994) where lower than physiologically normal P4 concentrations occur following the use of $\mathrm{P} 4$ inserts. Regression or ovulation of the dominant follicle and synchronous emergence of a new wave of follicle development may be achieved with the use of GnRH analogs (Twagiramungu et al., 1995; Roche et al., 1999).

The Ovsynch program involves an injection of $\mathrm{GnRH}$ $7 \mathrm{~d}$ before and $2 \mathrm{~d}$ after injection of $\mathrm{PGF}_{2 \alpha}$, with fixedtime artificial insemination (FTAI) occurring between 0 and $24 \mathrm{~h}$ after the second GnRH injection. Such programs have been widely evaluated for synchronization of ovulation in dairy and beef cattle (Pursley et al., 1995; Stevenson et al., 1996, 1999; Lamb et al., 2001). In several studies in mixed groups of cycling and anovular cows, Ovsynch programs have not improved pregnancy rates compared with insemination after detected estrus (Cordoba and Fricke, 2002; Gümen et al., 2003). Specifically in anovular cows, Ovsynch did not improve any measure of fertility compared with insemination on detection of estrus (Gümen et al., 2003).

The pregnancy rate with Ovsynch programs is generally improved by 10 to $20 \%$ by incorporation of $\mathrm{P} 4$ during the period between the first $\mathrm{GnRH}$ and $\mathrm{PGF}_{2 \alpha}$ in both beef (Lamb et al., 2001) and dairy cows (ElZarkouny et al., 2004; Melendez et al., 2006; Stevenson et al., 2008). However, in one study, no effect was seen (experiment 2 of El-Zarkouny et al., 2004). The increased pregnancy rates following addition of $\mathrm{P} 4$ occur in those cows that have low $\mathrm{P} 4$ concentrations preced- ing the $\mathrm{PGF}_{2 \alpha}$ injection (Lamb et al., 2001; Stevenson et al., 2006). This occurs both in cows not cycling at the commencement of treatment that fail to ovulate following the first GnRH injection and in those previously cycling cows that undergo luteolysis preceding the $\mathrm{PGF}_{2 \alpha}$ (Stevenson et al., 2006). Addition of progesterone to an Ovsynch program resulted in greater plasma P4 concentrations $14 \mathrm{~d}$ after FTAI than Ovsynch alone (Melendez et al., 2006) in cows not responding to a presynchrony program.

Fixed-time insemination is commonly used with Ovsynch programs and has the advantage of not requiring estrous detection. The proportion of animals displaying estrus in Ovsynch programs is low because the second GnRH induces ovulation before the large follicle has produced sufficient estradiol to induce behavioral estrus. The conception rates in cows that do display estrus before insemination are greater than those that do not in programs in which the second $\mathrm{GnRH}$ is replaced by an estrogen (e.g., EB or estradiol cypionate; Galvão et al., 2004). Delaying the second GnRH until $72 \mathrm{~h}$ after the PGF ${ }_{2 \alpha}$ with concurrent FTAI (Cosynch-72) may allow continued growth of the dominant follicle, a greater proportion of cows to express estrus, and hence, a greater conception rate. Cosynch-72 resulted in a greater pregnancy rate than Ovsynch or Cosynch-48 (i.e., with the second GnRH and FTAI concurrent at 48 $\mathrm{h}$ after $\mathrm{PGF}_{2 \alpha}$ ) in one study (Portaluppi and Stevenson, 2005). However, pregnancy rates did not differ between Cosynch-48 and Cosynch-72 in 2 other studies (Sterry et al., 2007; Brusveen et al., 2008). Cows that were injected with GnRH $56 \mathrm{~h}$ after $\mathrm{PGF}_{2 \alpha}$ and then inseminated $16 \mathrm{~h}$ later (Ovsynch-56) had greater pregnancy rates than Cosynch-48- or Cosynch-72-treated cows (Brusveen et al., 2008).

Under current New Zealand dairy management systems, those cows that are not detected in estrus by $10 \mathrm{~d}$ before the commencement of the breeding program are commonly presented for veterinary examination and treatment, whereas those that have been detected in estrus are left untreated and bred on detection of estrus once the breeding program has commenced. Ovsynch, Ovsynch and P4, and Cosynch-72 treatments of anestrous cows have not been assessed in seasonal calving, pasture-fed dairy management systems. The aim of the present study was to assess 3 treatment protocols for anoestrous cows compared with cows left untreated and bred following detection of estrus.

Specifically, we hypothesized that 1) treatment of anestrous cows would result in earlier conception than no treatment, 2) addition of $\mathrm{P} 4$ to Ovsynch would increase conception and pregnancy rates compared with Ovsynch alone, 3) there would be no difference in conception and pregnancy rates between cows treated 


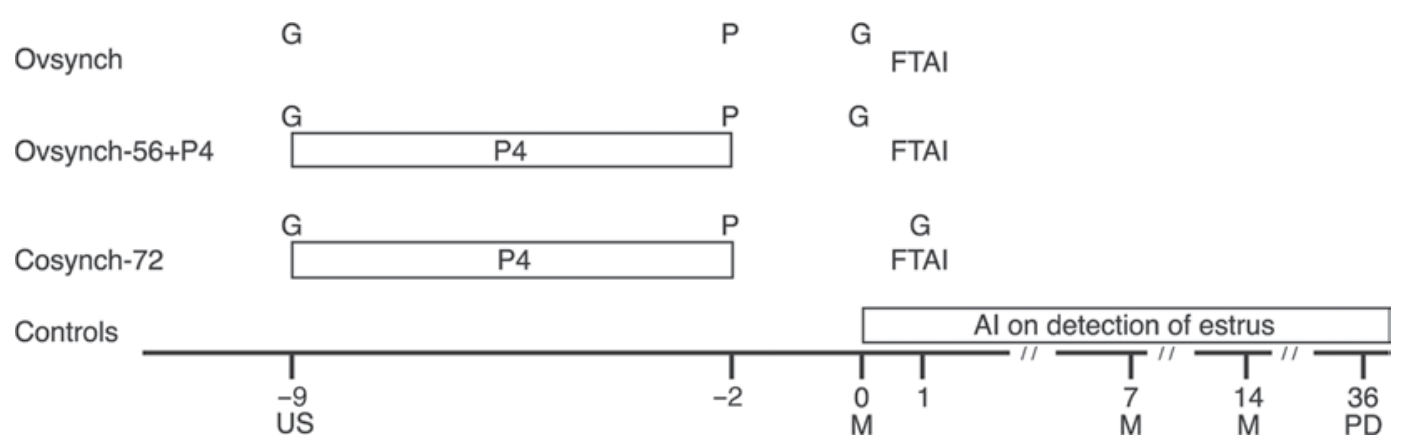

Figure 1. Schematic of the experimental design. Ovaries of cows not detected in estrus (as defined by presence of tail paint) by $9 \mathrm{~d}$ before the start of breeding were examined by ultrasonography (US) to define the presence of a corpus luteum. Cows were randomly assigned within each herd to be treated with (1) Ovsynch, (2) Ovsynch-56+P4, or (3) Cosynch-72+P4 or (4) to be left as untreated controls. Milk samples (M) were collected from a subset of cows in groups 1 and 2 at d 0,7 , and 14. Pregnancy diagnosis by ultrasonography (PD) occurred, on average, 36, 71, and $130 \mathrm{~d}$ after the start of breeding. FTAI $=$ fixed-time $\mathrm{AI} ; \mathrm{G}=\mathrm{GnRH} ; \mathrm{P}=\mathrm{PGF}_{2 \alpha} ; \mathrm{P} 4=$ intravaginal progesterone-releasing insert.

with Ovsynch or Ovsynch and $\mathrm{P} 4$ in those cows with a CL present at commencement of treatment, and 4) delaying the second $\mathrm{GnRH}$ injection to about $72 \mathrm{~h}$ after $\mathrm{PGF}_{2 \alpha}$ would result in more cows in estrus and greater conception rate to first service compared with a similar regimen but with the second $\mathrm{GnRH}$ injection occurring about $48 \mathrm{~h}$ after $\mathrm{PGF}_{2 \alpha}$.

\section{MATERIALS AND METHODS}

\section{Cows and Treatments}

This study was approved by the Animal Ethics Committee of AgResearch, Ruakura, New Zealand. Cows (n $=2,222$ from 12 herds) that had not been detected in estrus, or from which tail paint had not been removed in the $40 \mathrm{~d}$ before the start of the seasonal breeding program and which had been calved more than $30 \mathrm{~d}$, were enrolled. The average calving date was August 6, 2007, and ranged between June 11 and September 25,2007 . The average milk yield was $21.3 \mathrm{~kg} /$ cow per day $(\mathrm{SD}=2.3)$, with a fat test of $4.6 \%(\mathrm{SD}=0.35 \%)$ and a protein test of $3.6 \%(\mathrm{SD}=0.1 \%)$ at the production recording in the month preceding the start of the breeding program. Cows were fed predominantly white clover (Trifolium repens) and rye grass (Lolium perenne) pasture. All herds had a mineral supplementation program generally including magnesium oxide, selenium, and copper.

At enrollment (d-9), the reproductive tracts of the cows were palpated by a veterinarian, and the presence of any palpable uterine or ovarian pathology resulted in exclusion of the cow. Each ovary was examined using ultrasonography (ALOKA 500 with a 5-MHz transducer, Oceania-Pacific, Sydney, Australia), and the presence of a CL was determined. Body condition score was recorded on a 1-to-10 scale (Roche et al., 2004).
Cows were assigned within sequentially presented groups of 4 cows within each herd to treatment with one of the following (Figure 1):

1. Injection of $100 \mu \mathrm{g}$ of gonadorelin $(1 \mathrm{~mL}$ of Ovurelin, Bomac Laboratories Ltd., Manukau City, New Zealand) at d $-9,500 \mu \mathrm{g}$ of sodium cloprostenol $\left(\mathrm{PGF}_{2 \alpha} ; 2 \mathrm{~mL}\right.$ of Ovuprost, Bomac Laboratories Ltd.) at d -2 (after a.m. milking), and $100 \mu \mathrm{g}$ of gonadorelin at d 0 (p.m. milking), with FTAI approximately $16 \mathrm{~h}$ after the final GnRH treatment (Ovsynch).

2. As for (1) but with application of an intravaginal progesterone-releasing insert between d 9 and $\mathrm{d}$ 2 (Ovsynch-56+P4).

3. As for (2) but with the second GnRH injection delayed until approximately $71 \mathrm{~h}$ after $\mathrm{PGF}_{2 \alpha}$ (i.e., d 1) and with FTAI 0 to $5 \mathrm{~h}$ later for those cows that had not been detected in estrus and inseminated by that time (Cosynch- $72+\mathrm{P} 4$ ).

4. No treatment (negative control group).

A randomized treatment list was prepared for each herd by using a random number generator add-in in Excel 2007 (Random Number Generator, www.add-ins. com). There were no differences among treatments in age, breed category, days calved, or BCS (all $P>0.15$; Table 1).

Two types of intravaginal P4-releasing inserts were used in the study: an insert containing $1.38 \mathrm{~g}$ of $\mathrm{P} 4$ (CIDR Cattle Insert, Pfizer Animal Health Ltd., Auckland, New Zealand) and another containing $1.56 \mathrm{~g}$ of $\mathrm{P} 4$ (Cue-Mate, Bomac Laboratories Ltd., Auckland, New Zealand). Within each farm, the 2 inserts were used in a systematic fashion by undertaking a coin toss to assign the first treatment and then alternating P4 inserts 
Table 1. Descriptive data for enrolled cows not detected in estrus, by treatment

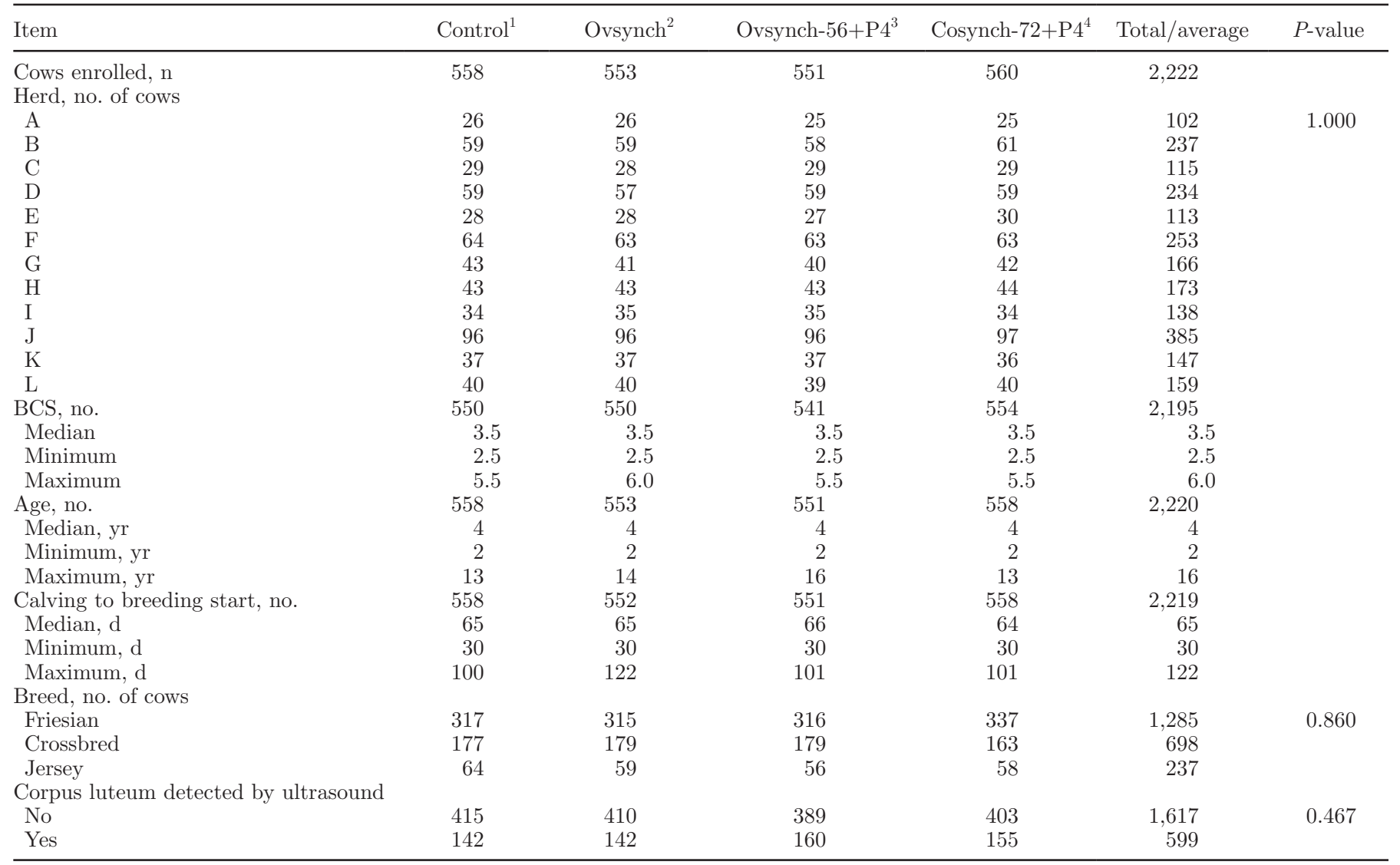

${ }^{1}$ Untreated control.

${ }^{2} \mathrm{GnRH}, \mathrm{PGF}_{2 \alpha}$, and $\mathrm{GnRH}$ at 7- and 2-d intervals, respectively, and with fixed-time insemination approximately $16 \mathrm{~h}$ after the final GnRH.

${ }^{3} \mathrm{GnRH}, \mathrm{PGF}_{2 \alpha}$, and $\mathrm{GnRH}$ at 7- and 2-d intervals, respectively, and insertion of an intravaginal progesterone-releasing insert at the time of the first $\mathrm{GnRH}$ treatment, with fixed-time insemination approximately $16 \mathrm{~h}$ after the final $\mathrm{GnRH}$.

${ }^{4} \mathrm{GnRH}, \mathrm{PGF}_{2 \alpha}$, and GnRH at 7- and 3-d intervals, respectively, and insertion of an intravaginal progesterone-releasing insert at the time of the first $\mathrm{GnRH}$ treatment, with fixed-time insemination concurrent with the final GnRH.

with sequential animals requiring $\mathrm{P} 4$ treatment (i.e., Ovsynch-56+P4 and Cosynch-72+P4 treatments).

Cows detected in estrus in any treatment from $\mathrm{d}-1$ onward were inseminated. Estrus detection was performed based on observation of tail paint on a twicedaily basis, with cows from which tail paint had been removed being defined as in, or having been in, estrus. Cows seen standing upon being ridden by other cows while in the holding yards before milking were also defined as being in estrus. The second GnRH injection was not given when a cow had been detected in estrus at the time that this injection was programmed to occur. The interval between $\mathrm{PGF}_{2 \alpha}$ and the second $\mathrm{GnRH}$ averaged 55:24 (hh:mm; $\mathrm{SD}=00: 31$; range $=54: 15$ to 56:00) for the Ovsynch and Ovsynch-56+P4 treatments and 70:56 $(\mathrm{SD}=00: 43$; range $=69: 51$ to $72: 00)$ for the Cosynch- $72+\mathrm{P} 4$ treatment. Artificial insemination was administered by experienced technicians, and inseminations occurred between approximately 09:00 and 13:00 h. That is, AI was programmed to occur approximately 72 to $76 \mathrm{~h}$ after $\mathrm{P} 4$-insert removal and $\mathrm{PGF}_{2 \alpha}$ injection and 16 to $22 \mathrm{~h}$ after the second $\mathrm{GnRH}$ injection for cows in the Ovsynch and Ovsynch-56+P4 treatments and 0 to $5 \mathrm{~h}$ after the second GnRH for the Cosynch$72+\mathrm{P} 4$ treatment. Cows in the control treatment were inseminated upon detection of estrus from $\mathrm{d}-1$.

Following the initial FTAI, any cow detected in estrus, irrespective of previous treatment, was bred by AI for an average of $38.0 \mathrm{~d}$ ( $\mathrm{SD}=7.8$; range $=24$ to 52 ). Following this, entire bulls of beef breeds were introduced to the herds. The total breeding period averaged $95.3 \mathrm{~d}$ ( $\mathrm{SD}=6.4$, range $=81$ to 106$)$. A total of $23 \mathrm{AI}$ technicians were used, of which 17 did more than 20 inseminations. In the majority of herds, one technician did the majority of inseminations, i.e., one technician did $>60 \%$ of the inseminations in 10 of the 12 herds. The additional technicians were enlisted when a large number of cows were programmed to be inseminated on 
one day. Semen from a total of 141 AI sires was used, but 22 of these sires were used for 20 or more inseminations and contributed $>75 \%$ of the inseminations. Bull breeding dates were recorded in 10 of the 12 herds.

Pregnancy status and stage of gestation for those cows detected as pregnant were estimated for all cows $36 \mathrm{~d}(\mathrm{SD}=1.2$, range $=35$ to 38$)$ and $71 \mathrm{~d}(\mathrm{SD}=$ 1.0 , range $=69$ to 72 ) after the start of the breeding program. All animals were again examined approximately $5 \mathrm{wk}$ after the bulls were finally removed from the herds. Transrectal ultrasonography (ALOKA 500 with a $5-\mathrm{MHz}$ transducer) was used to estimate the stage of gestation in days at each examination, and the date of conception was calculated by subtracting the number of days pregnant from the date of examination. When this estimated day of conception was within 7 $\mathrm{d}$ of a recorded AI or bull breeding (when data were available), the recorded breeding date was accepted as the day of conception. When the estimated date deviated $>7 \mathrm{~d}$ from the last recorded date, the estimated conception date was used as the conception date in subsequent analyses. Cows that died or were removed from the herd before pregnancy diagnosis were included in submission-rate analyses up to the date of culling but removed from pregnancy-rate analyses and right censored in the survival analysis. The final estimated conception date was used for cows that were initially confirmed as pregnant but were subsequently found to have aborted and reconceived. Those cows that aborted and failed to reconceive were defined as not having conceived at all for the conception-rate and pregnancy-rate analyses. All cows in the study were assigned a final status of pregnant (i.e., conceived and remained pregnant at the final pregnancy test), confirmed not pregnant at the final pregnancy test (which occurred $>35$ $\mathrm{d}$ after removal of the bull), or not detectably pregnant (i.e., were not defined as pregnant at the most recent pregnancy test but were removed from the herd before the final pregnancy test occurred and, hence, the final status could not be defined).

The analysis was on an intention to treat basis; that is, the denominator for the submission- and pregnancyrate analyses was the entire enrolled population of cows, irrespective of whether the full treatment protocol was adhered to. However, when the final pregnancy status was not detectably pregnant, the cow was not included in the denominator for the final pregnancy-rate model.

The denominator of the conception rate to first service within $21 \mathrm{~d}$ of the start of breeding included all cows that had a breeding within $21 \mathrm{~d}$ of the start of breeding and were presented for pregnancy testing. The interval from the start of breeding to conception was calculated by subtracting the date of conception from the date on which breeding started for the herd. Cows that were not pregnant or not detectably pregnant at the last pregnancy test undertaken (i.e., removed before the final pregnancy test after bull removal had occurred) were right censored, and the start of breeding to conception interval in days was defined as the entire breeding period for the nonpregnant cows and the last pregnancy test date $-35 \mathrm{~d}$ (the minimum interval at which pregnancy could be defined), the date on which the breeding program started, for cows not detectably pregnant.

\section{Milk Sample Collection and Analysis}

Milk samples $(\sim 5 \mathrm{~mL})$ were collected from a subset of 306 cows (154 from the Ovsynch treatment and 152 from the Ovsych-56+P4 treatment) on d 0,7 , and 14 for subsequent $\mathrm{P} 4$ concentration determination. It was determined a priori that a subset of 150 cows would provide sufficient statistical power $(\alpha=0.05 ; \beta=0.2)$ to detect a $15 \%$ difference in the proportion of cows with a milk progesterone concentration $>1 \mathrm{ng} / \mathrm{mL}$, assuming $70 \%$ of the Ovsynch group had milk progesterone concentrations $>1 \mathrm{ng} / \mathrm{mL}$. Thus, not all cows in the treatment groups were required to test the hypothesis that more of the Ovsynch-56+P4 group would have milk progesterone concentrations $>1 \mathrm{ng} / \mathrm{mL}$ than the Ovsynch group. These 2 groups were selected to test this hypothesis because they differed only in the presence or absence of the $\mathrm{P} 4$ device. Progesterone concentration was determined using an $\mathrm{I}^{125}$-labeled radioimmunoassay (Coat-a-Count progesterone assay, Diagnostic Products Corporation, Los Angeles, CA). The within and between assay ( $\mathrm{n}=6$ assays) variation coefficients of variation were 7.7 and $1.1 \%$ for a control sample with a concentration of $4.5 \mathrm{ng} / \mathrm{mL}$ (SD $=0.35$ ) and 7.7 and $5.3 \%$ for a control sample with a concentration of $0.47 \mathrm{ng} / \mathrm{mL}(\mathrm{SD}=0.04)$, respectively. The minimum detectable concentration was $0.06 \mathrm{ng} /$ $\mathrm{mL}$. The CL was defined as functional when the P4 concentration was $>1 \mathrm{ng} / \mathrm{mL}$.

\section{Animal Data}

Data including age (yr), calving date, calving type (i.e., normal, aborted, induced, or farmer or veterinarian assisted), number of calves born (i.e., one or 2 calves born), breed, CL status at examination (i.e., CL detected or not detected on ultrasonography), BCS at $\mathrm{d}-9$, all recorded $\mathrm{AI}$ and natural breeding dates, removal date and reason, and pregnancy diagnoses were retrieved from a database (Livestock Improvement Corporation, Hamilton, New Zealand), veterinary records, or herd records. 


\section{Statistical Analyses}

Cows were entirely excluded from analysis if they had missing calving dates $(\mathrm{n}=3)$, missing breed data $(\mathrm{n}=$ $2)$, or missing age data $(n=2)$. In models in which a variable that had missing values was included (e.g., CL status at enrollment, BCS at enrollment), case-wise removal of those specific cases occurred and so the number of cases varied between models.

Seven $(1.3 \%)$ and $6(1.1 \%)$ cows were not recorded in estrus and were not recorded as having been treated with GnRH on d 0 from the Ovsynch and Ovsynch$56+\mathrm{P} 4$ treatments, respectively. One cow $(0.2 \%)$ in the Cosynch-72+P 4 treatment was incorrectly injected with GnRH on d 0. Nineteen (3.4\%) cows in the Cosynch$72+\mathrm{P} 4$ treatment were not presented (or recorded as having been detected in estrus) on $\mathrm{d} 1$, and one cow in the Ovsynch-56+P4 treatment was incorrectly treated with GnRH on d 1. No control cows were recorded as incorrectly having been given any treatments. Because the data set was analyzed on an intention to treat basis, those cows not receiving the correct treatment were left in the subsequent analyses. Analysis on an intention to treat basis results in more conservative inferences and reflects the fact that under field conditions, it is common that not every cow receives all designated treatments (Dohoo et al., 2003). Analysis on an intention to treat basis has been recommended for analysis of randomized controlled trials because it reduces the risk of bias and provides a truer test of effectiveness of the treatment than analysis following case-wise deletion of cows with missing data (Peduzzi et al., 2002).

Balance of treatments for age, milk yield and composition, BCS, interval from calving to start of the breeding program, and the total length of the breeding program was compared using $\chi^{2}$ (for categorical variables) or one-way ANOVA (for continuous variables). Data are presented as medians, minimums, and maximums in Table1.

Outcome variables of interest included the proportion of cows inseminated by d 21 after the start of breeding (d 0; i.e., number of cows inseminated by d $21 \div$ total number of enrolled cows), the proportion of cows that conceived at first insemination when that insemination occurred within $21 \mathrm{~d}$ of the start of breeding (i.e., number of cows confirmed pregnant to insemination by $\mathrm{d}$ $21 \div$ total number of cows inseminated by $\mathrm{d} 21$ ), the proportion of cows pregnant by d 21 and d 42 after the start of breeding (i.e., number of cows confirmed pregnant by d 21 or $42 \div$ total number of enrolled cows), and the proportion of cows pregnant at the end of the breeding program. Note that a small number (n $=26$ ) of cows were inseminated on $\mathrm{d}-1$, and these were included as having been bred (and conceived, if that occurred) by d 21 or 42 .

The main predictor variable was treatment (i.e., control vs. Ovsynch vs. Ovsynch- $56+\mathrm{P} 4$ vs. Cosynch$72+\mathrm{P} 4)$. However, several other variables that were potential confounders were also evaluated. These variables included the CL status at enrollment (i.e., CL present or absent), herd, age (coded as 2 to $3,4,5$ to 6 , and $>6$ yr of age), breed (categorized as Friesian or Jersey if that breed was $>11 / 16$ th of the cow's genetics, all others were categorized as crossbred), BCS (coded as $<4,4$, and $>4$ ), and DIM at the start of breeding (categorized as $>83 \mathrm{~d}, 63$ to $83 \mathrm{~d}, 42$ to $62 \mathrm{~d}$, and 30 to $41 \mathrm{~d}$ ). Because a different AI technician undertook the majority of inseminations within each herd and, similarly, because one veterinarian undertook the diagnosis of CL presence in each herd, inclusion of either AI technicians or veterinarian in multivariable models that included herd resulted in failure of the models to converge. Hence, these 2 variables were not included in any models.

Descriptive analyses (including calculation of means, standard deviation, standard error of the mean, minimum and maximum, as well as frequency tables or histograms of the data) were performed on all variables to check for outlying values and inconsistencies. Initially, the univariate associations between the outcome variables of interest and the predictor variables were examined using $\chi^{2}$ analysis for categorical predictor variables and logistic regression for continuous predictor variables. Those variables associated (i.e., $P<0.2$ ) were then included in a generalized linear model (GENLIN procedure within SPSS, SPSS Corp., Chicago, IL) with a logit binomial structure. Variables were removed if they were nonsignificant $(P>0.05)$, if they did not improve the goodness of fit as assessed using Akaike's information criterion, and if the coefficient estimate for the treatment effects did not alter by $>10 \%$. The estimated marginal means for each treatment were calculated, and the treatments were compared on a pair-wise basis using the Bonferroni adjustment for multiple comparisons. First-order interactions between treatment and the other significant main effects were examined and included in the final model where $P<$ 0.05. Because the outcomes were not rare (i.e., $>10 \%$ ), relative risks, rather than odds ratios, are the more appropriate measure (McNutt, 2003). Hence, a generalized linear model was also constructed using binomial/ log structure because the coefficients from these models exponentiate to relative risk (McNutt, 2003).

Survival-analysis techniques were used to investigate the effect of treatment on days from start of breeding to conception. Initially, Kaplan-Meier analyses were un- 
dertaken, and variables with significant log-rank tests at levels of $P<0.2$ were used for multivariable modeling. Daily hazard of conception was estimated using a Cox's proportional hazards model. Model building was conducted in a forward, manual, step-wise manner, with variables retained in the model when likelihood ratio statistic was $P \leq 0.05$ or when a change of $>15 \%$ in the coefficient of the treatment variable occurred. The data are presented as the mean and median days from the start of breeding to conception (from the Kaplan-Meier analyses) and graphically as the 1 - cumulative survival proportion by days after the start of breeding. The differences among treatments were tested by undertaking pair-wise comparisons using the Breslow test.

The milk progesterone concentrations at $\mathrm{d} 0,7$, and 14 were not normally distributed (data not shown), and $\log _{10}$ transformation did not normalize the data. Hence, the data were dichotomized into $\leq 1 \mathrm{ng} / \mathrm{mL}$ and $>1 \mathrm{ng} /$ $\mathrm{mL}$ for further analysis. Univariate (i.e., $\chi^{2}$ ) analyses were used to assess the effect of treatment (i.e., Ovsynch vs. Ovsynch-56+P4) and CL status at enrollment (yes or no) on the proportion that had milk progesterone $>1 \mathrm{ng} / \mathrm{mL}$ at each time point. Mantel-Haenszel analysis was used to test whether the relationship between treatment and milk progesterone status was the same between those cows that did and did not have a CL at enrollment.

The interval (in days) between the first and second breeding (when it occurred and was recorded) was calculated for each cow. The effect of treatment on the distribution of these intervals was examined by creating a histogram of the intervals by treatment. The intervals were then classified as short (i.e., $<18 \mathrm{~d}$ ) or not short (i.e., $\geq 18 \mathrm{~d}$ ). This dichotomized variable was then analyzed using a generalized linear model with a binomial logit link function, the estimated marginal means (and standard errors) were calculated, and the treatments were compared using the sequential Bonferroni adjustment for multiple comparisons. The explanatory variables were treatment, CL status at enrollment, and the interaction.

There was no difference between cows treated with the 2 intravaginal $\mathrm{P} 4$ inserts in age, calving date, or BCS (all $P>0.2$ ). In addition, there were no differences in pregnancy rates by d 21 or 42 , final pregnancy rate, proportion of cows with milk $\mathrm{P} 4$ concentrations $>1 \mathrm{ng} / \mathrm{mL}$ at $\mathrm{d} 7$ and 14 , proportion of cows with short interservice intervals, or the median interval to conception (all $P>0.2$ ) between cows treated with the $2 \mathrm{P} 4$ inserts. Thus, for all further analysis, the data from the 2 P4 inserts were combined.

Data were entered into a Microsoft Access database, and statistical analysis was carried out in SPSS 15.1
(SPSS Corp.). Statistical significance was set at a level of $P \leq 0.05$ for all analyses.

\section{RESULTS}

\section{Cows in Estrus Before the Final GnRH Injection}

More of the cows in the Ovsynch-56+P4 compared with the Ovsynch treatment were detected in estrus by d 0 [186/545 (34.1\%) vs. $121 / 546(22.2 \%) ; P<0.001]$. More cows with a CL present at initiation of treatment were detected in estrus on $\mathrm{d} 0$ than were those without a $\mathrm{CL}[36.9 \%(\mathrm{SEM}=3.8 \%)$ vs. $25.5 \%(\mathrm{SEM}=2.5 \%)$; $P<0.001]$. Cows $>83$ or 63 to 83 DIM at the start of the breeding program were more likely to be in estrus than those calving later $(P<0.001)$. Fewer Friesians $[22.2 \%(\mathrm{SEM}=2.3 \%)]$ were in estrus on d 0 than either crossbreds $[32.8 \%(\mathrm{SEM}=3.2 \%)]$ or Jerseys $[39.0 \%$ $(\mathrm{SEM}=6.4 \%) ; P<0.001]$. There was variation among herds in the proportion in estrus on d 0 [range $=12.9 \%$ $(\mathrm{SEM}=4.8 \%)$ to $54.7 \%(\mathrm{SEM}=6.9 \%) ; P<0.001]$. Within the Ovsynch treatment, those cows that had a CL were more likely $(P<0.05)$ than those that did not have a CL to be detected in estrus on $\mathrm{d} 0$, whereas in the Ovsynch- $56+\mathrm{P} 4$ treatment, there was no effect of presence of CL on the proportion in estrus on $\mathrm{d}$ 0 . There were no significant interactions between the treatment and any of the other main effects left in the final model. A total of 257 out of 541 cows (47.5\%) in the Cosynch-72+P4 treatment were detected in estrus before the scheduled time of the second GnRH injection, and this treatment was not given.

\section{Twenty-One-Day Submission Rate}

Fewer cows were inseminated within $21 \mathrm{~d}$ in the control treatment than in the other 3 treatments $(P<$ 0.001 ; Table 2). The 21-d submission rate varied among herds $(P<0.001)$, increased with increasing cow age $(P$ $<0.002$ ), was less in Friesian than Jersey or crossbred cows $(P<0.001)$, and was greater in animals that were detected with a CL before the start of treatment than in those without a CL $(P<0.001)$.

\section{First-Service Conception Rate}

First-service conception rate in the Ovsynch-56+P4 treatment was greater than in the Ovsynch and control treatment but did not differ from the Cosynch- $72+\mathrm{P} 4$ treatment (Table 2). First-service conception rate was greater in cows having a CL before treatment $[43.1 \%$ $(\mathrm{SEM}=2.4 \%)]$ than in those without a CL $[33.4 \%$ $(\mathrm{SEM}=1.7 \%)]$. Cows $>83$ or 63 to $83 \mathrm{DIM}$ at the start 
Table 2. Reproductive performance of anestrous cows by treatment

\begin{tabular}{|c|c|c|c|c|c|}
\hline Item $^{1}$ & Control $^{2}$ & Ovsynch $^{3}$ & Ovsynch- $56+\mathrm{P} 4^{4}$ & Cosynch- $72+\mathrm{P} 4^{5}$ & $P$-value \\
\hline \multicolumn{6}{|c|}{ Bred by d $21^{6}$} \\
\hline EMM & $79.8^{\mathrm{a}}$ & $99.5^{\mathrm{b}}$ & $99.9^{\mathrm{b}}$ & $99.4^{\mathrm{b}}$ & \multirow[t]{2}{*}{$<0.001$} \\
\hline SEM & 2.8 & 0.2 & 0.1 & 0.2 & \\
\hline \multicolumn{6}{|c|}{ Conception $\mathrm{S}^{7}$} \\
\hline EMM & $34.3^{\mathrm{a}}$ & $33.9^{\mathrm{a}}$ & $45.7^{\mathrm{b}}$ & $39.0^{\mathrm{ab}}$ & \multirow[t]{2}{*}{$<0.001$} \\
\hline SEM & 2.5 & 2.4 & 2.6 & 2.5 & \\
\hline \multicolumn{6}{|c|}{ Pregnant d $21^{8}$} \\
\hline EMM & $36.2^{\mathrm{a}}$ & $48.4^{\mathrm{b}}$ & $57.5^{\mathrm{b}}$ & $50.9^{\mathrm{b}}$ & \multirow[t]{2}{*}{$<0.001$} \\
\hline SEM & 2.9 & 3.2 & 3.2 & 3.1 & \\
\hline \multicolumn{6}{|c|}{ Pregnant d $42^{9}$} \\
\hline EMM & 67.9 & 72.7 & 72.9 & 69.3 & \multirow[t]{2}{*}{0.18} \\
\hline SEM & 2.6 & 2.4 & 2.4 & 2.6 & \\
\hline \multicolumn{6}{|c|}{ Pregnant final ${ }^{10}$} \\
\hline EMM & 93.3 & 93.9 & 93.9 & 93.1 & \multirow[t]{2}{*}{0.88} \\
\hline SEM & 1.2 & 1.1 & 1.1 & 1.2 & \\
\hline
\end{tabular}

a,b Means with different superscripts within a row differ at $P<0.05$.

${ }^{1} \mathrm{EMM}=$ estimated marginal mean.

${ }^{2}$ Untreated control.

${ }^{3} \mathrm{GnRH}, \mathrm{PGF}_{2 \alpha}$, and $\mathrm{GnRH}$ at 7- and 2-d intervals, respectively, and with fixed-time insemination approximately $16 \mathrm{~h}$ after the final GnRH.

${ }^{4} \mathrm{GnRH}, \mathrm{PGF}_{2 \alpha}$, and $\mathrm{GnRH}$ at 7- and 2-d intervals, respectively, and insertion of an intravaginal progesteronereleasing insert at the time of the first $\mathrm{GnRH}$ treatment, with fixed-time insemination approximately $16 \mathrm{~h}$ after the final GnRH.

${ }^{5} \mathrm{GnRH}, \mathrm{PGF}_{2 \alpha}$, and $\mathrm{GnRH}$ at 7- and 3-d intervals, respectively, and insertion of an intravaginal progesteronereleasing insert at the time of the first $\mathrm{GnRH}$ treatment, with fixed-time insemination concurrent with the final GnRH.

${ }^{6}$ Percentage of cows bred by d 21 of the breeding program.

${ }^{7}$ Percentage conceiving to first insemination.

${ }^{8}$ Percentage pregnant within the first $21 \mathrm{~d}$ of the breeding program.

${ }^{9}$ Percentage pregnant within the first $42 \mathrm{~d}$ of the breeding program.

${ }^{10}$ Percentage pregnant by the end of the breeding program.

of the breeding program had greater first-service conception rates than did those calving later $(P<0.001)$. Cows with a BCS of 4 had a greater first-service conception rate than those with a BCS $<4$ but were no different from those with a BCS $>4(P<0.01)$. There was variation among herds in the first-service conception rate range $=24.4 \%(\mathrm{SEM}=4.2 \%)$ to $50.5 \%(\mathrm{SEM}=$ $3.8 \%) ; P<0.001]$. There were no interactions between treatment and any of the other main effects left in the final model.

The first-service conception rate was greater in those cows designated to be treated with $\mathrm{GnRH}$ but who came into estrus before treatment and, hence, were not given the second GnRH compared with those cows not in estrus. In the Cosynch- $72+\mathrm{P} 4$ treatment, those cows that were detected in estrus had a conception rate of $47.4 \%$ (120/253) compared with $25.6 \%$ (69/270) for those cows not detected in estrus and injected with the second GnRH $(P<0.001)$. Similarly, cows detected in estrus preceding the second GnRH injection had a greater conception rate than those not in estrus in both the Ovsynch (29.4 vs. $40.3 \%$ ) and Ovsynch-56+P4 treatments (36.6 vs. 58.3\%; Mantel-Haenszel $\chi^{2} P<$ 0.001).

\section{Day 21 Pregnancy Rate}

Fewer cows were pregnant by $\mathrm{d} 21$ in the control treatment than in the other 3 treatments $(P<0.001$; Table 2). The d 21 pregnancy rate of cows in the Ovsynch-56+P4 treatment did not differ from the rate of those in the Cosynch-72+P4 treatment $(P=0.51)$ but tended to be greater than the rate of those in the Ovsynch treatment $(P=0.12)$. However, there was a treatment-by-DIM interaction $(P=0.05)$ whereby the $\mathrm{d} 21$ pregnancy rate was unaffected by DIM in the control treatment but decreased with fewer DIM in the other 3 treatments (Figure 2). The d 21 pregnancy rate was greater in cows with a CL present at enrollment $[52.6 \%(\mathrm{SEM}=2.7 \%)]$ compared with those without a CL $[43.7 \%(\mathrm{SEM}=2.2) ; P<0.001]$. Cows $>6 \mathrm{yr}$ old had lesser d 21 pregnancy rates than did 4-yr-old cows $(P=0.006)$. Cows with a BCS $<4$ had lesser d 21 pregnancy rates $[43.7 \%(\mathrm{SEM}=2.2 \%)]$ than those with a BCS of $4[51.4 \%(\mathrm{SEM}=2.7 \%)]$, with those with a BCS $>4$ being intermediate $[49.4 \%(\mathrm{SEM}=3.6 \%) ; P=$ 0.014 for $<4$ vs. 4 and $P=0.39$ for $<4$ vs. $>4]$. There was variation among herds in the $\mathrm{d} 21$ pregnancy rate (range $=32.3$ to $62.5 \% ; P<0.001$ ). Friesians had lesser 


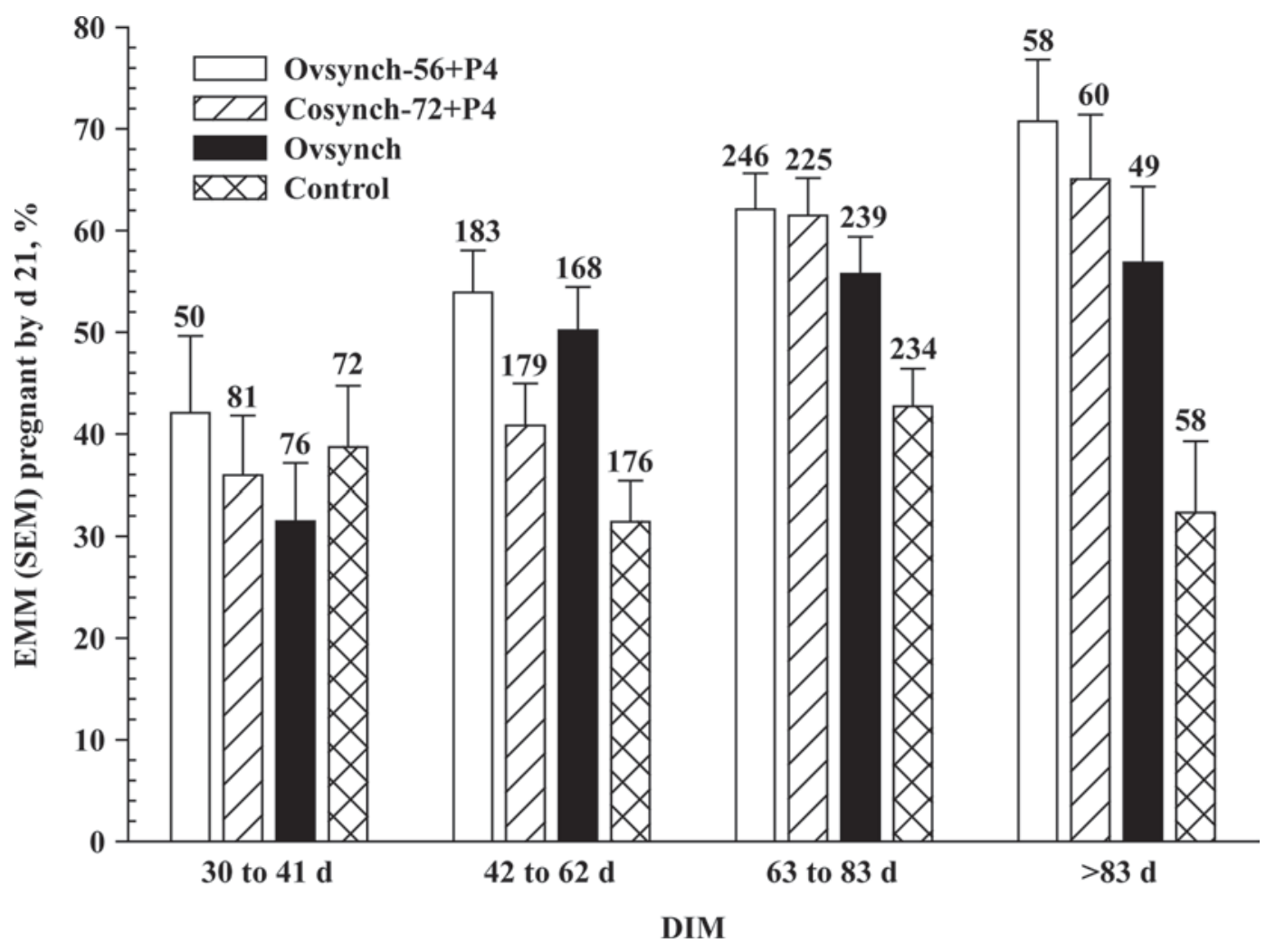

Figure 2. The estimated marginal means (EMM) and SEM for d 21 pregnancy rate by treatment and by DIM at the start of breeding. The number above each bar represents the number of cows in that treatment in that range of DIM. Ovsynch-56+P4 $=\mathrm{GnRH}, \mathrm{PGF}{ }_{2 \alpha}$, and $\mathrm{GnRH}$ at 7- and 2-d intervals, respectively, and insertion of an intravaginal progesterone-releasing insert at the time of the first GnRH treatment, with fixed-time insemination approximately $16 \mathrm{~h}$ after the final $\mathrm{GnRH}$. Cosynch-72+P4 = GnRH, PGF $2 \alpha$, and GnRH at 7- and 3-d intervals, respectively, and insertion of an intravaginal progesterone-releasing insert at the time of the first GnRH treatment, with fixed-time insemination concurrent with the final GnRH. Ovsynch $=\mathrm{GnRH}, \mathrm{PGF}_{2 \alpha}$, and $\mathrm{GnRH}$ at 7- and 2-d intervals, respectively, and with fixed-time insemination approximately $16 \mathrm{~h}$ after the final $\mathrm{GnRH}$.

d 21 pregnancy rates $[45.3 \%(\mathrm{SEM}=2.2 \%)]$ than did crossbreds $[53.1 \%(\mathrm{SEM}=2.4 \%)]$ but had similar rates to those of Jerseys [46.1\% (SEM $=4.5 \%) ; P<0.001]$. There were no interactions between the treatment and any of the other main effects left in the final model.

\section{Day 42 Pregnancy Rate}

The d 42 pregnancy rate did not differ among the treatments $(P=0.18$; Table 2$)$. Day 42 pregnancy rate was greater in cows with a CL present at enrollment $[73.8 \%(\mathrm{SEM}=2.2 \%)]$ than in those without a CL $[67.5 \%(\mathrm{SEM}=2.1 \%) ; P<0.001]$. Cows $>83$ or 63 to 83 DIM at the start of the breeding program had a greater d 42 pregnancy rate than those calving later $(P<0.001)$. Cows with a BCS $<4$ had a lesser d 42 pregnancy rate $[64.6 \%(\mathrm{SEM}=2.1 \%)]$ than did cows with a BCS of $4[72.9 \%(\mathrm{SEM}=2.3 \%)]$ or $>4[74.3 \%$ $(\mathrm{SEM}=2.9 \%) ; P<0.001]$. Cows $<4$ yr old had a lesser d 42 pregnancy rate than did older cows $(P<0.001)$. There was variation among herds in the $\mathrm{d} 42$ pregnancy rate $($ range $=59.9$ to $80.0 \% ; P<0.001$ ). Friesians had lesser d 42 pregnancy rates $[66.8 \%(\mathrm{SEM}=2.0 \%)]$ than did crossbreds $[72.9 \%(\mathrm{SEM}=2.1 \%)]$ or Jerseys $[72.3 \%$ $(\mathrm{SEM}=3.8 \%) ; P<0.001]$. There were no interactions between treatment and any of the other main effects left in the final model.

\section{Final Pregnancy Rate}

The final pregnancy rate did not differ among treatments $(P=0.94$; Table 2$)$. Cows $>83$ DIM at the start of the breeding program had greater final pregnancy rates than did those who were 30 to 41 DIM ( $P=$ $0.02)$.

\section{Analysis of the Interval from the Start of Breeding to Conception (Survival Analyses)}

Cows in all 3 treatments conceived earlier than the controls (all $P<0.001$; Figure 3). Cows in the Ovsynch$56+\mathrm{P} 4$ treatment conceived earlier than those in the Ovsynch treatment $(P<0.05)$ in both CL-negative and CL-positive cows and overall (Table 3 ). Cows with a 


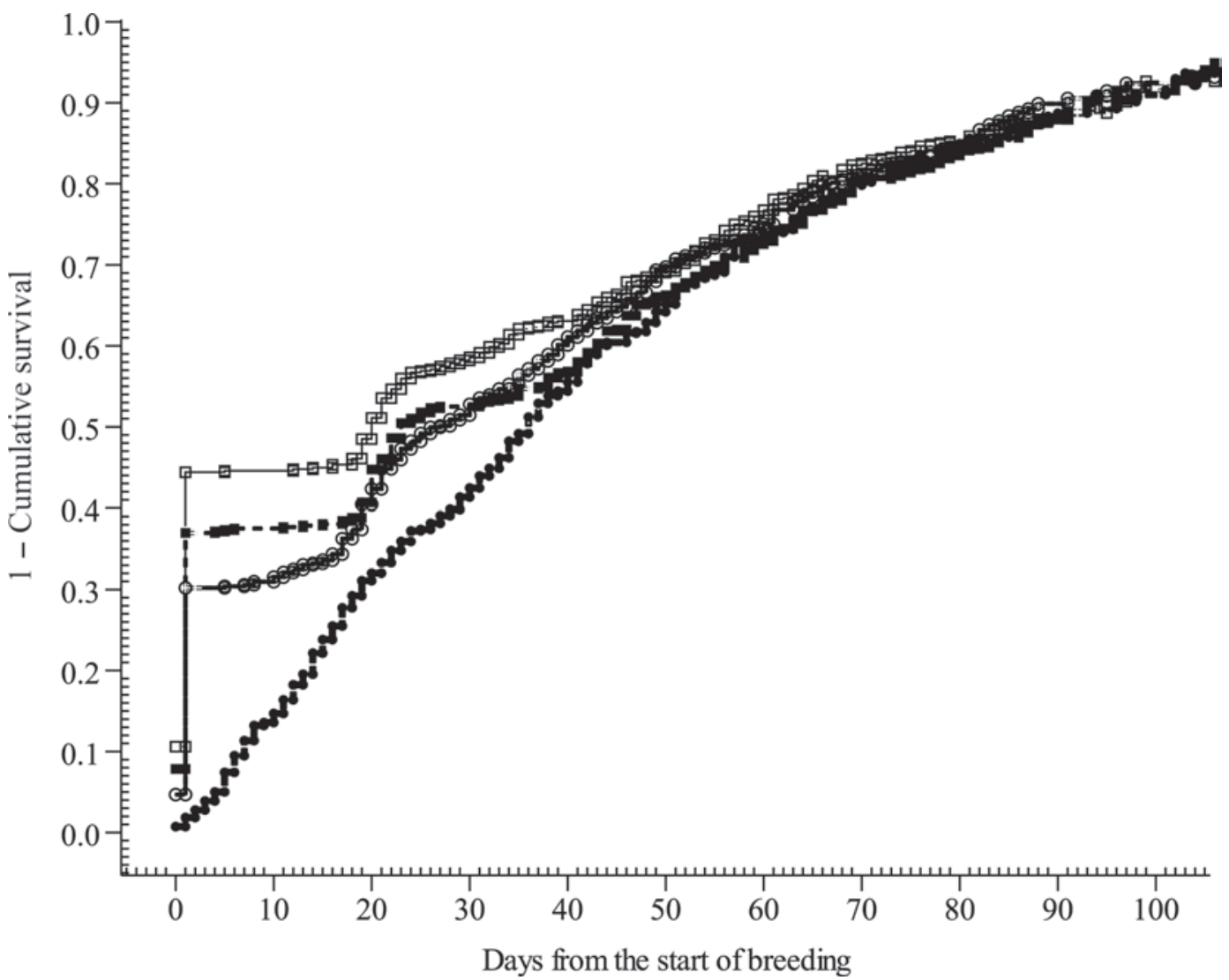

Figure 3. The 1 - cumulative survival hazard for cows not detected in estrus by $9 \mathrm{~d}$ before the seasonal breeding program and treated with

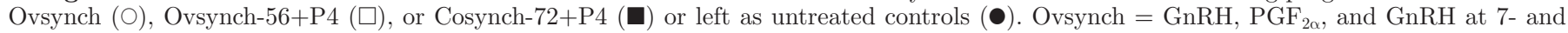
2 -d intervals, respectively, and with fixed-time insemination approximately $16 \mathrm{~h}$ after the final GnRH. Ovsynch-56+P4 $=\mathrm{GnRH}, \mathrm{PGF}_{2 \alpha}$, and $\mathrm{GnRH}$ at 7- and 2-d intervals, respectively, and insertion of an intravaginal progesterone-releasing insert at the time of the first GnRH treatment, with fixed-time insemination approximately $16 \mathrm{~h}$ after the final GnRH. Cosynch-72+P4 = GnRH, PGF $2 \alpha$, and GnRH at 7- and 3-d intervals, respectively, and insertion of an intravaginal progesterone-releasing insert at the time of the first GnRH treatment, with fixed-time insemination concurrent with the final GnRH.

CL present at enrollment conceived earlier than those without a CL $(P<0.001$; Table 3$)$ and had a shorter mean $[32.1 \mathrm{~d}(\mathrm{SE}=1.4)$ vs. $38.3 \mathrm{~d}(\mathrm{SE}=0.9)]$ and median $[21.0 \mathrm{~d}(\mathrm{SE}=1.3)$ vs. $31 \mathrm{~d}(\mathrm{SE}=1.7)]$ interval from start of breeding to conception. There was no interaction of CL presence and treatment $(P=0.58)$.

Cows $>83$ or 63 to 83 DIM at the start of the breeding program conceived earlier than cows calving later (Table 4). Cows with a BCS $<4$ conceived later than those with a BCS of 4 or $>4$ (Table $4 ; P<0.001$ ). Friesians conceived later than crossbreds (Table $4 ; P$ $<0.001)$. Cows $<4$ yr old conceived later than 4 -yr-old or 5 - to 6 -yr-old cows (Table $4 ; P<0.001$ ). There was variation among herds in the rate of conception $(P<$ 0.001). There were no interactions between treatment and the other main effects.

\section{Milk P4 Concentrations Posttreatment}

More cows treated with Ovsynch than with Ovsynch-56+P4 had elevated (i.e., $>1 \mathrm{ng} / \mathrm{mL}$ ) milk
P4 concentrations on d $0[13 / 154(8.4 \%)$ vs. $0 / 152$ (0\%) $P<0.001]$. Conversely, fewer cows had elevated milk P4 concentrations in the Ovsynch treatment than in the Ovsynch- $56+\mathrm{P} 4$ treatment on both $\mathrm{d} 7$ [114/154 (74.0\%) vs. $133 / 154(87.5 \%) ; P=0.03]$ and d 14 [92/154 (59.7\%) vs. $121 / 152(79.6 \%) ; P<0.001]$. More cows with a CL at enrollment had elevated milk P4 concentrations at d 14 than those without a CL at enrollment $[82 / 101(81.2 \%)$ vs. $130 / 204(63.7 \%) ; P$ $=0.002]$. Fewer cows in the Ovsynch treatment had elevated milk P4 concentrations at d 14 than cows in the Ovsynch-56+P4 treatment, both in cows without a CL at enrollment $[60 / 107(56.1 \%)$ vs. $70 / 97(72.2 \%) ; P$ $=0.012]$ and in those with a CL at enrollment $[32 / 46$ $(69.6 \%)$ vs. $60 / 54(92.6 \%) ; P=0.003]$. There was no interaction between CL presence and treatment on the proportion of cows with an elevated $\mathrm{P} 4$ concentration on $\mathrm{d} 14(P=0.11)$.

More cows with elevated milk $\mathrm{P} 4$ at d 14 were pregnant by $\mathrm{d} 21$ than those with low progesterone [124/210 
Table 3. The mean and median intervals in days from the start of breeding to conception by presence or absence of a corpus luteum (CL) at initiation of treatment

\begin{tabular}{|c|c|c|c|c|c|c|c|c|c|c|}
\hline \multirow[b]{2}{*}{ CL present } & \multirow[b]{2}{*}{ Treatment } & \multirow[b]{2}{*}{ Mean } & \multirow[b]{2}{*}{$\mathrm{SE}$} & \multicolumn{2}{|c|}{$95 \% \mathrm{CI}$} & \multirow[b]{2}{*}{ Median } & \multirow[b]{2}{*}{$\mathrm{SE}$} & \multicolumn{2}{|c|}{$95 \% \mathrm{CI}$} & \multirow{2}{*}{$\begin{array}{l}\text { Group } \\
\text { difference }^{1}\end{array}$} \\
\hline & & & & Lower & Upper & & & Lower & Upper & \\
\hline \multirow[t]{5}{*}{ No } & Control $^{2}$ & 43.5 & 1.6 & 40.5 & 46.6 & 37 & 1.8 & 33.5 & 40.5 & $\mathrm{a}$ \\
\hline & Ovsynch $^{3}$ & 37.0 & 1.7 & 33.6 & 40.4 & 30 & 3.1 & 23.9 & 36.1 & b \\
\hline & Ovsynch-56+P $44^{4}$ & 34.6 & 1.9 & 30.9 & 38.3 & 21 & 2.1 & 16.9 & 25.1 & c \\
\hline & Cosynch- $72+\mathrm{P} 4^{5}$ & 37.4 & 1.8 & 33.9 & 40.9 & 26 & 4.1 & 18.0 & 34.0 & $\mathrm{bc}$ \\
\hline & Overall & 38.3 & 0.9 & 36.5 & 40.0 & 31 & 1.7 & 27.7 & 34.3 & \\
\hline \multirow{3}{*}{ Yes } & Ovsynch-56+P4 & 26.2 & 2.6 & 21.0 & 31.4 & 1 & 1.9 & 0.0 & 4.7 & c \\
\hline & Cosynch-72+P4 & 32.3 & 3.0 & 26.5 & 38.2 & 20 & 2.0 & 16.1 & 23.9 & bc \\
\hline & Overall & 32.1 & 1.4 & 29.3 & 34.8 & 21 & 1.3 & 18.5 & 23.5 & \\
\hline \multirow[t]{4}{*}{ Combined } & Control & 42.2 & 1.3 & 39.5 & 44.8 & 36 & 1.7 & 32.7 & 39.3 & $\mathrm{a}$ \\
\hline & Ovsynch & 35.8 & 1.5 & 32.9 & 38.7 & 26 & 2.3 & 21.5 & 30.5 & b \\
\hline & Ovsynch- $56+\mathrm{P} 4$ & 32.1 & 1.6 & 29.0 & 35.1 & 20 & 2.1 & 15.8 & 24.2 & c \\
\hline & Cosynch-72+P4 & 36.0 & 1.5 & 33.0 & 39.0 & 23 & 3.6 & 16.0 & 30.0 & bc \\
\hline
\end{tabular}

${ }^{1}$ Differences among groups by pair-wise Breslow test statistic; treatments within each CL status with a different letter differ at $P<0.05$.

${ }^{2}$ Untreated control.

${ }^{3} \mathrm{GnRH}, \mathrm{PGF}_{2 \alpha}$, and $\mathrm{GnRH}$ at 7- and 2-d intervals, respectively, and with fixed-time insemination approximately $16 \mathrm{~h}$ after the final GnRH.

${ }^{4} \mathrm{GnRH}, \mathrm{PGF}_{2 \alpha}$, and $\mathrm{GnRH}$ at 7- and 2-d intervals, respectively, and insertion of an intravaginal progesterone-releasing insert at the time of the first $\mathrm{GnRH}$ treatment, with fixed-time insemination approximately $16 \mathrm{~h}$ after the final $\mathrm{GnRH}$.

${ }^{5} \mathrm{GnRH}, \mathrm{PGF}_{2 \alpha}$, and $\mathrm{GnRH}$ at 7- and 3-d intervals, respectively, and insertion of an intravaginal progesterone-releasing insert at the time of the first $\mathrm{GnRH}$ treatment, with fixed-time insemination concurrent with the final GnRH.

$(59.0 \%)$ vs. $9 / 90(10.0 \%) ; P<0.001]$. This effect was consistent across treatments.

\section{Interval Between First and Second Service}

A total of 1,044 cows $(47.0 \%$ of all cows) had a second breeding recorded. The proportion of cows with a short interservice interval (i.e., $<18$ d) varied among treatments $(P<0.001)$, with fewer of the cows that had been treated with $\mathrm{P} 4$ (i.e., the Ovsynch-56+P4 and Cosynch-72+P4 treatments) having a short interservice interval $[15.5 \%(\mathrm{SE}=2.5 \%)$ vs. $15.7 \%(\mathrm{SE}=2.6 \%)$ vs. $30.5 \%(\mathrm{SE}=3.0 \%)$ vs. $32.1 \%(\mathrm{SE}=3.5 \%)$ for $\mathrm{Co}-$ synch-72+P4, Ovsynch-56+P4, Ovsynch, and control treatments, respectively; $P<0.001$ for Cosynch- $72+\mathrm{P} 4$ vs. control, $P<0.001$ for Ovsynch-56+P4 vs. control, and $P=1.0$ for Ovsynch vs. control]. However, there was a CL-status-by-treatment interaction $(P=0.02)$; in controls, there was a tendency $(P=0.08)$ for fewer of the cows with a CL present to have a short interservice interval, whereas in the other treatments, there was no effect of presence or absence of a CL on the proportion with short intervals (Figure 4).

\section{Pregnancy Loss Between the First and Second Pregnancy Tests}

A total of $35(5.4 \%)$ of the 644 cows pregnant at the first pregnancy test were not detected pregnant at the second pregnancy test. Of these, $26(74.3 \%)$ were confirmed pregnant to a later service, $3(8.6 \%)$ were not detectably pregnant when last examined, and 6 (17.1\%) were confirmed not pregnant after the end of the breeding program. There was no difference in the pregnancy loss rates between treatments $[3 / 49(6.1 \%)$, $8 / 165$ (4.8\%), 8/231 (3.5\%), and 16/199 (8.0\%) for the control, Ovsynch, Ovsynch-56+P4, and Cosynch$72+\mathrm{P} 4$ treatments, respectively; $P=0.21$. Pregnancy loss was not associated with age, herd, CL presence, or DIM (all $P>0.2$ ).

\section{DISCUSSION}

This study demonstrated that treatment of anestrous cows resulted in cows conceiving earlier than with no treatment. In addition, the Ovsynch- $56+\mathrm{P} 4$ treatment resulted in earlier conception than the other treatments. Inclusion of P4 increased the proportion of cows with a CL on d 14 and decreased the proportion of cows with a short (i.e., $<18 \mathrm{~d}$ ) interservice interval. No difference in the $\mathrm{d} 42$ or final pregnancy rates was observed among treatments.

This study specifically examined the effects of treatment of cows not detected in estrus before the start of a seasonal breeding program in pasture-fed dairy cattle. Thus, this study differs in several ways from previous studies evaluating similar protocols. Cows were selected on the basis that they had not been detected in estrus 
Table 4. Hazard of pregnancy

\begin{tabular}{|c|c|c|c|c|c|c|}
\hline \multirow[b]{2}{*}{ Item } & \multirow[b]{2}{*}{ Wald } & \multirow[b]{2}{*}{$\mathrm{df}$} & \multirow[b]{2}{*}{$P$-value } & \multirow[b]{2}{*}{ Hazard } & \multicolumn{2}{|c|}{$95 \% \mathrm{CI}$} \\
\hline & & & & & Lower & Upper \\
\hline \multicolumn{7}{|l|}{ Treatment $^{1}$} \\
\hline Ovsynch $^{2}$ & 4.2 & 1 & 0.040 & 1.143 & 1.006 & 1.298 \\
\hline Ovsynch $-56+\mathrm{P} 4^{3}$ & 7.5 & 1 & 0.006 & 1.196 & 1.052 & 1.360 \\
\hline Cosynch- $72+\mathrm{P} 4^{4}$ & 3.0 & 1 & 0.083 & 1.119 & 0.985 & 1.271 \\
\hline \multicolumn{7}{|l|}{ Age, ${ }^{5}$ yr } \\
\hline 4 & 13.6 & 1 & 0.000 & 1.305 & 1.133 & 1.503 \\
\hline 5 to 6 & 9.7 & 1 & 0.002 & 1.214 & 1.074 & 1.371 \\
\hline$>6$ & 0.1 & 1 & 0.776 & 1.019 & 0.894 & 1.162 \\
\hline \multicolumn{7}{|l|}{$\mathrm{BCS}^{6}$} \\
\hline 4 & 8.8 & 1 & 0.003 & 1.179 & 1.057 & 1.313 \\
\hline$>4$ & 4.2 & 1 & 0.040 & 1.168 & 1.007 & 1.354 \\
\hline \multicolumn{6}{|l|}{$\mathrm{DIM}^{8}$} & 1.288 \\
\hline 63 to $83 \mathrm{~d}$ & 1.2 & 1 & 0.269 & 0.916 & 0.784 & 1.070 \\
\hline 42 to $62 \mathrm{~d}$ & 13.2 & 1 & 0.000 & 0.738 & 0.626 & 0.869 \\
\hline 30 to $41 \mathrm{~d}$ & 22.9 & 1 & 0.000 & 0.619 & 0.509 & 0.754 \\
\hline \multicolumn{7}{|l|}{ Breed $^{9}$} \\
\hline Crossbred & 6.4 & 1 & 0.011 & 1.150 & 1.032 & 1.282 \\
\hline Jersey & 0.4 & 1 & 0.524 & 1.064 & 0.879 & 1.289 \\
\hline
\end{tabular}

${ }^{1}$ Reference category $=$ control treatment.

${ }^{2} \mathrm{GnRH}, \mathrm{PGF}_{2 \alpha}$, and $\mathrm{GnRH}$ at 7- and 2-d intervals, respectively, and with fixed-time insemination approximately $16 \mathrm{~h}$ after the final GnRH.

${ }^{3} \mathrm{GnRH}, \mathrm{PGF}_{2 \alpha}$, and $\mathrm{GnRH}$ at 7- and 2-d intervals, respectively, and insertion of an intravaginal progesteronereleasing insert at the time of the first $\mathrm{GnRH}$ treatment, with fixed-time insemination approximately $16 \mathrm{~h}$ after the final GnRH.

${ }^{4} \mathrm{GnRH}, \mathrm{PGF}_{2 \alpha}$, and $\mathrm{GnRH}$ at 7- and 3-d intervals, respectively, and insertion of an intravaginal progesteronereleasing insert at the time of the first GnRH treatment, with fixed-time insemination concurrent with the final GnRH.

${ }^{5}$ Reference category $=2$ - and 3 -yr-old cows.

${ }^{6}$ Reference category $=$ BCS $<4$ at enrollment.

${ }^{7}$ Reference category $=$ absence of CL at enrollment.

${ }^{8}$ Reference category $=$ DIM $>83 \mathrm{~d}$.

${ }^{9}$ Reference category $=$ Friesian .

based on a combination of no observed signs of estrus and no removal of tail paint. This differs from previous studies in which generally all cows were enrolled, irrespective of ovulatory status, and were retrospectively classified based on progesterone concentrations. The current population included both cows that were anovular and those that had ovulated and had not been detected in estrus. Under New Zealand field conditions, these are the cows routinely presented for veterinary examination and treatment. Due to the seasonal breeding program, there is no defined period after calving in which breeding is not undertaken. That is, even if a cow has been calved a few weeks, it will be bred if detected in estrus once the seasonal breeding program has started. Thus, cows entered the treatment programs on average about $65 \mathrm{~d}$ after calving but ranged from 30 to over 100 $\mathrm{d}$ calved at that time. This differs from previous studies in which cows have been enrolled in relatively narrow $(<2 \mathrm{wk})$ windows. The cows in the current study were pasture fed, and under these management conditions, cows produce, on average, 3,570 L/lactation (LIC and DairyNZ, 2008), less than for herds fed total mixed rations and housed. Thus, the results of the current study extend the previous studies evaluating similar treatments because the enrollment criteria for the cows and the production system in which the treatments were evaluated differ from those previously used.

The finding of a positive effect of treatment on the interval from start of breeding to conception is in agreement with a previous study in which a $\mathrm{P} 4$ and $\mathrm{EB}$ protocol resulted in anestrous cows conceiving $15 \mathrm{~d}$ earlier than with no treatment (McDougall and Compton, 2005). The earlier conception was associated with both a greater proportion of cows being bred and a similar or greater conception rate than for the control cows. Whereas almost $80 \%$ of the control cows were detected in estrus and bred in the first $21 \mathrm{~d}$ of the breeding program, by definition, $100 \%$ of the treated cows were bred either following detection or by FTAI in the first $24 \mathrm{~h}$ of the breeding program. An even larger advantage 


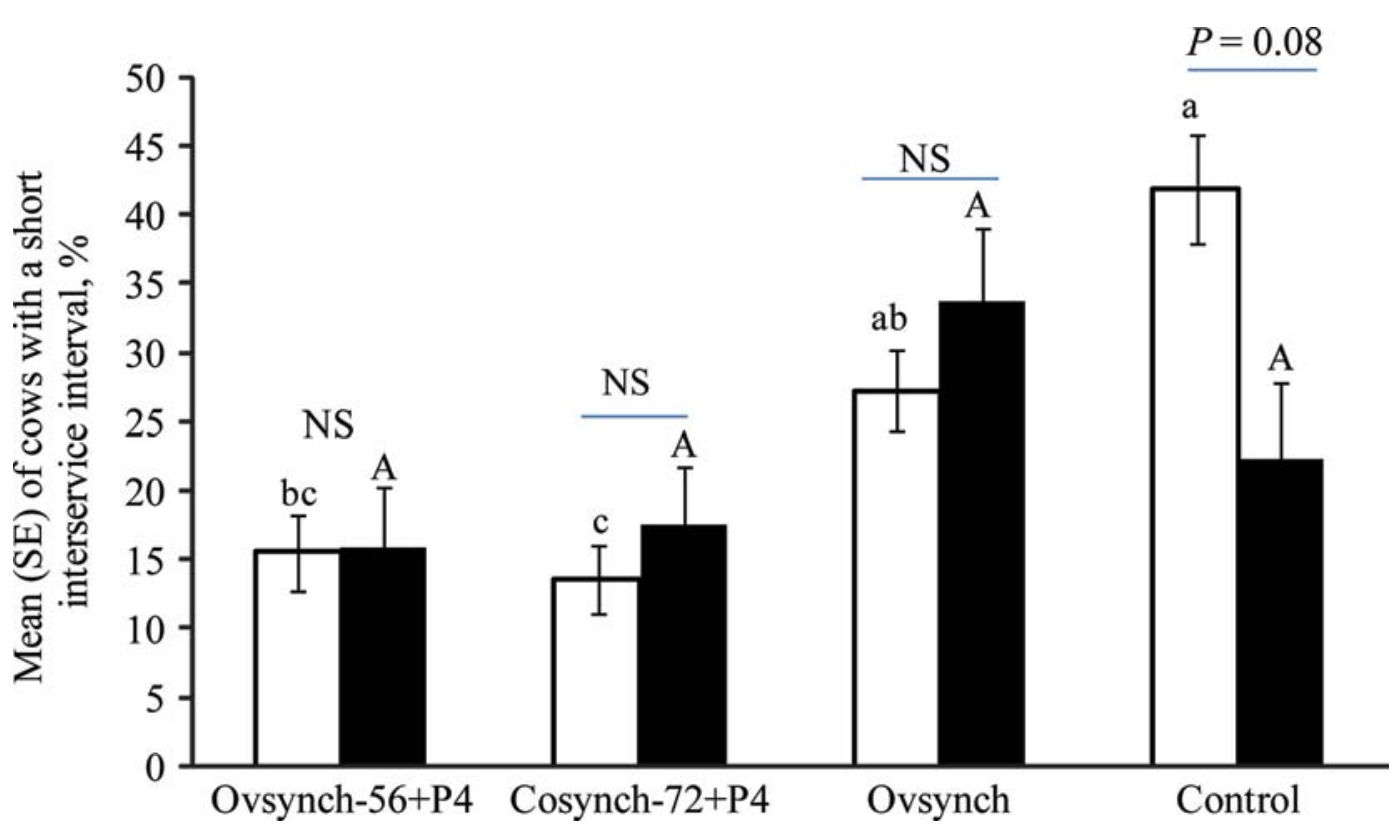

Figure 4. The estimated marginal mean (SE) percentage of cows with a short (i.e., $<18 \mathrm{~d}$ ) interservice interval for cows not detected in estrus before the planned start of breeding and treated with Ovsynch, Ovsynch-56+P4, or Cosynch-72+P4 or left as untreated controls and with (CL+; black bars) and without (CL-; white bars) a corpus luteum (CL) at the time of initiation of treatment. Within each CL status (lowercase letters for CL- cows and uppercase letters for CL+ cows), treatments with different letters differ at $P<0.05$. The horizontal lines above the treatments indicate the significance of within-treatment effect of CL status. Ovsynch $=$ GnRH, PGF ${ }_{2 \alpha}$, and GnRH at 7- and 2-d intervals, respectively, and with fixed-time insemination approximately $16 \mathrm{~h}$ after the final GnRH. Ovsynch-56+P4 $=\mathrm{GnRH}, \mathrm{PGF}_{2 \alpha}$, and $\mathrm{GnRH}$ at $7-$ and 2-d intervals, respectively, and insertion of an intravaginal progesterone-releasing insert at the time of the first GnRH treatment, with fixed-time insemination approximately $16 \mathrm{~h}$ after the final GnRH. Cosynch-72+P4 $=\mathrm{GnRH}, \mathrm{PGF}_{2 \alpha}$, and GnRH at 7- and 3-d intervals, respectively, and insertion of an intravaginal progesterone-releasing insert at the time of the first GnRH treatment, with fixed-time insemination concurrent with the final GnRH. Color version available in the online PDF.

of treatment might occur if fewer of the control cows expressed estrus or if the sensitivity of estrus detection was less.

Addition of $\mathrm{P} 4$ to the Ovsynch program (Ovsynch$56+\mathrm{P} 4)$ resulted in a $12 \%$ greater first-service conception rate, a (nonsignificant) $9 \%$ greater pregnancy rate by $\mathrm{d} 21$, and a median conception date $6 \mathrm{~d}$ earlier than for Ovsynch alone. This is in general agreement with the majority of studies not using presynchronization, in which the addition of $\mathrm{P} 4$ to Ovsynch programs resulted in greater pregnancy rates in beef (Lamb et al., 2001) and dairy (Stevenson et al., 2006) cattle. However, when presynchronization is used, $\mathrm{P} 4$ appears to offer no benefit over Ovsynch alone (El-Zarkouny et al., 2004 (experiment 2); Galvão et al., 2004). Ovsynch and P4 increased pregnancy rates by $8 \%$ (31.2 vs. $22.7 \%$ ) compared with Ovsynch in one study in which cows that were not detected in estrus following presynchronization were then treated (Melendez et al., 2006). Cows in that study were not assessed for cyclic status before initiation of treatment, but it is likely that a majority were not cycling, similar to the cows in the current study. It has been demonstrated that the addition of $\mathrm{P} 4$ increases pregnancy rates when the plasma $\mathrm{P} 4$ concen- trations are $<1 \mathrm{ng} / \mathrm{mL}$ but not when plasma $\mathrm{P} 4$ is $\geq 1$ $\mathrm{ng} / \mathrm{mL}$ at the time of the $\mathrm{PGF}_{2 \alpha}$ treatment (Stevenson et al., 2006). The plasma P4 concentrations were not determined at this time in the current study because under practical situations, the plasma $\mathrm{P} 4$ status is not known and treatment protocol decisions are made before this time. Addition of $\mathrm{P} 4$ increased pregnancy rate by $8 \%$ in cows presynchronized and found not to have a CL upon ultrasonography at the time of initiation of the Ovsynch program (Stevenson et al., 2008). In that study, all cows with a CL were treated with Ovsynch without additional P4. The current study extends pervious findings by demonstrating that adding $\mathrm{P} 4$ to Ovsynch results in earlier conception, even for cows with a CL present at initiation of treatment.

In cows, the first postpartum ovulation is often not accompanied by estrus, and the subsequent luteal phase is often short (Webb et al., 1980). Progesterone treatment preceding induction of first postpartum ovulation results in more cows having a normal-length subsequent luteal phase (Sheffel et al., 1982; Fike et al., 1997). It had been initially hypothesized that for cows with a CL at the initiation of treatment, addition of $\mathrm{P} 4$ to the Ovsynch treatment (Ovsynch-56+P4) 
would not improve conception or pregnancy rates over Ovsynch alone. This was because those cows with a CL were likely to have already been exposed to P4, so no additional effect of exogenous $\mathrm{P} 4$ above that of the endogenous $\mathrm{P} 4$ was expected. However, there were no CL-by-treatment interactions for the first-service conception rate, pregnancy rate at d 21 or 42, final pregnancy rate, or in the hazard of conception. In addition, more Ovsynch-56+P4 than Ovsynch treated cows had elevated milk P4 concentrations at d 14, both in cows with and without a CL present at initiation of treatment, and they were less likely to have a short interservice interval. Thus, $\mathrm{P} 4$ treatment resulted in more cows having a CL at d 14, even when a CL was present at the start of treatment. It is possible that misclassification of cows occurred and that some of the cows diagnosed with a CL did not in fact have a CL. The specificity of ultrasonography for a CL is reported to be $88 \%$; that is, $12 \%$ of cows without a functional CL (as defined by a serum progesterone concentration of $>1 \mathrm{ng} / \mathrm{mL}$ ) were found to have a CL upon ultrasound (Silva et al., 2007) and $21 \%$ of cows with a serum P4 concentration of $<0.5 \mathrm{ng} / \mathrm{mL}$ had a CL (Stevenson et al., 2008). However, because the CL is detectable from a few days after ovulation and also following functional luteolysis when the plasma P4 concentrations are $<1$ $\mathrm{ng} / \mathrm{mL}$ (Battocchio et al., 1999; McDougall and Rhodes, 1999), many cows apparently falsely diagnosed with a CL, based on plasma $\mathrm{P} 4$, are likely to truly have a CL. Diagnosis of the presence of CL at some time point does not, however, ensure that the subsequent ovulation is followed by a luteal phase of normal length or a normal conception rate. Between 30 and $50 \%$ of postpartum dairy cattle have abnormalities in luteal phase lengths before breeding (Lamming and Darwash, 1998; Opsomer et al., 1998). For example, $12 \%$ of cows have intervals of $>12 \mathrm{~d}$ between the demise of a CL and the rise of $\mathrm{P} 4$ in the subsequent luteal phase (Lamming and Darwash, 1998). A previous study found that CL-positive anestrous cows take $4 \mathrm{~d}$ longer to conceive and have a lesser final pregnancy rate than cycling herdmates (McDougall and Rhodes, 1999). Under current New Zealand management programs for anestrous cows, some veterinarians choose either to use Ovsynch alone or to use no treatment for anestrous cows in which a CL is detected. The current study suggests that both CL-positive and CL-negative anestrous cows do benefit from treatment including $\mathrm{P} 4$ and that detection of a CL in an anestrous cow does not indicate that the cow would not benefit from addition of $\mathrm{P} 4$ to Ovsynch.

As originally hypothesized, delaying the second $\mathrm{GnRH}$ treatment until $72 \mathrm{~h}$ after removal of the $\mathrm{P} 4$ insert and $\mathrm{PGF}_{2 \alpha}$ injection (Cosynch-72+P4) resulted in more cows being detected in estrus. In the current study, the proportion in estrus increased from $34 \%$ in the Ovsynch-56+P4 to $46 \%$ in the Cosynch-72+P4 treatments. In addition, cows in estrus preceding the final GnRH injection had greater conception rates, both when scheduled for treatment on d 0 (i.e., the Ovsynch and Ovsynch-56+P4 treatments) and on $\mathrm{d} 1$ (i.e., the Cosynch-72+P4 treatment). A similar result has been demonstrated previously following use of the heatsynch protocol (Galvão et al., 2004). However, overall, there were no differences in conception or pregnancy rates, or in interval between start of breeding and conception, between the Cosynch-72+P4 and Ovsynch-56+P4 treatments. The conception rate following FTAI in the absence of preceding estrus was only $26 \%$ in Cosynch-72+P4-treated cows compared with $37 \%$ for the Ovsynch-56+P4-treated cows. Thus, any benefit of an increased proportion of cows in estrus was negated by numerically poorer overall first-service conception rate in the Cosynch- $72+\mathrm{P} 4$ treatment. It has previously been demonstrated that Ovsynch- 56 results in a greater pregnancy rate than does Cosynch-72 (Brusveen et al., 2008). Those authors suggest the improved pregnancy rate may be related to insemination occurring at a more optimal time relative to ovulation for Ovsynch-56 compared with Cosynch-72.

Cows $>6$ yr old had lesser d 21 pregnancy rates than 4 -yr-old cows, but cows $<4$ yr old had lesser d 42 pregnancy rates than older cows. This apparent anomaly may be due to the hazard of pregnancy declining in the $<4$-yr-old cows relative to other groups between approximately d 20 to d 60 of breeding (data not presented). The reasons for this are not clear but may be associated with fewer cows in this age group being bred (either following detection of estrus and AI or naturally bred) or this age group having lesser conception rates at these breedings. Because not all bull breeding dates were recorded, analysis of submission- and conceptionrate differences among age groups during this period cannot be undertaken in the current study.

The pregnancy loss rate did not differ among the treatments in the current study. This is in agreement with Stevenson et al. (2006), who found no difference in pregnancy loss rates between Ovsynch- and Ovsynch+P4-treated cows. However, a tendency for a greater pregnancy loss rate following Cosynch-72 compared with Ovsynch-56 was observed in multiparous cows in another study (Brusveen et al., 2008). The loss rate in the current study was $6 \%$, similar to that observed by Brusveen et al. (2008) but less than the $21 \%$ reported by Stevenson et al. (2006). Reasons for the differences among studies are not clear.

Because the previously used $\mathrm{P} 4$ and $\mathrm{EB}$ protocol was not included in the current study design, because the ban occurred before this study was undertaken, direct 
comparison of that program with those of the current study cannot be made. However, numerically, the firstservice conception rate, proportion of cows pregnant by d 56 of the breeding program, and the median interval to conception were similar. For example, in a previous study using $\mathrm{P} 4$ and $\mathrm{EB}$ protocols in anestrous cows, the first-service conception proportion was 0.47 , the proportion of cows pregnant by d 56 was 0.70 , the final in-calf proportion was 0.86 , and the treated cows conceived approximately $15 \mathrm{~d}$ earlier than the control group (McDougall and Compton, 2005). In comparison, the equivalent figures in the current study (i.e., from the Ovsynch-56+P4-treated, CL-negative group) were $0.41,0.71,0.93$, and $16 \mathrm{~d}$, respectively.

Although the pregnancy rate by $\mathrm{d} 42$, or the end of the breeding program, did not differ among the treatments, earlier conception is likely to result in an economic benefit for treated anestrous cows. This is because in a seasonal breeding system, the interval from the start of breeding to conception is well correlated with the interval from the start of the seasonal calving period to actual calving because gestation length is not altered by treatment. Given that herds usually dry all cows off on one calendar day, cows calving later in the subsequent season have a shorter lactation length. Hence, neither the d 42 nor the final pregnancy rate strongly influence the cost/benefit of treatments. Rather, the return is dependent on the calving date, lactation length, proportion of anestrous cows, and the proportion of cows that produce calves sired by AI (as distinct from natural mating) in the subsequent lactation (McDougall and Compton, 2006).

In conclusion, the initial hypothesis that treatment of anestrous cows would result in earlier conception than no treatment was accepted. Inclusion of $\mathrm{P} 4$ in the Ovsynch treatment resulted in earlier conception compared with Ovsynch alone. The hypothesis that inclusion of $\mathrm{P} 4$ in the Ovsynch protocol would not benefit those cows with CL present at initiation of treatment was rejected because inclusion of $\mathrm{P} 4$ resulted in earlier conception in both CL-negative and CL-positive cows. Finally, the Cosynch-72 treatment did result in more cows being detected in estrus before the final $\mathrm{GnRH}$ treatment, but overall, this treatment did not increase first-service conception rate relative to the Ovsynch$56+\mathrm{P} 4$ treatment.

\section{ACKNOWLEDGMENTS}

The cooperation of the herd owners involved in the study is much appreciated. The technical support of Laura Clausen, Katie Carnie, Sarah Clune, Rhonda Cooper, Murray Edgar, Alfred Gerrits, Vickii van Gog, Ondine Habgood, Jirigala Menghe, Cathy Yanez, and
Angela Sheehan (DairyNZ) is appreciated. Veterinary procedures (ovarian palpation, ovarian ultrasonography, and pregnancy testing) were undertaken by Chris Compton, Andrew Gore, John McCarthy, Angela McEwan, Geoff Plant, Katrina Roberts, and Matt Wells, all of the Animal Health Centre, Morrinsville, New Zealand.

The study was funded by DairyNZ (1/6), DairyAustralia (1/6), Bomac Laboratories (1/3), and Pfizer $(1 / 3)$. The Cue-mates, GnRH and $\mathrm{PGF}_{2 \alpha}$, were supplied by Bomac and the CIDR-B by Pfizer.

\section{REFERENCES}

Battocchio, M., G. Gabai, A. Mollo, M. C. Veronesi, F. Soldano, G. Bono, and F. Cairoli. 1999. Agreement between ultrasonographic classification of the CL and plasma progesterone concentration in dairy cows. Theriogenology 51:1059-1069.

Bo, G. A., G. P. Adams, R. A. Pierson, and R. J. Mapletoft. 1995. Exogenous control of emergence of follicle waves in cattle. Theriogenology 43:31-40.

Brusveen, D. J., A. P. Cunha, C. D. Silva, P. M. Cunha, R. A. Sterry, E. P. B. Silva, J. N. Guenther, and M. C. Wiltbank. 2008. Altering the time of the second gonadotropin-releasing hormone injection and artificial insemination (AI) during ovsynch affects pregnancies per AI in lactating dairy cows. J. Dairy Sci. 91:1044-1052.

Cordoba, M. C., and P. M. Fricke. 2002. Initiation of the breeding season in a grazing-based dairy by synchronization of ovulation. J. Dairy Sci. 85:1752-1763.

Dohoo, I., W. Martin, and H. Stryhn. 2003. Veterinary Epidemiologic Research. AVC Inc., Prince Edward Island, Canada.

El-Zarkouny, S. Z., J. A. Cartmill, B. A. Hensley, and J. S. Stevenson. 2004. Pregnancy in dairy cows after synchronized ovulation regimens with or without presynchronization and progesterone. J. Dairy Sci. 87:1024-1037.

Fike, K. E., M. L. Day, E. K. Inskeep, J. E. Kinder, P. E. Lewis, R. E. Short, and H. D. Hafs. 1997. Estrus and luteal function in suckled beef cows that were anestrous when treated with an intravaginal device containing progesterone with or without a subsequent injection of estradiol benzoate. J. Anim. Sci. 75:2009-2015.

Fourichon, C., H. Seegers, and X. Malher. 2000. Effect of disease on reproduction in the dairy cow: A meta-analysis. Theriogenology 53:1729-1759.

Galvão, K. N., J. E. Santos, S. O. Juchem, R. L. Cerri, A. C. Coscioni, and M. Villaseñor. 2004. Effect of addition of a progesterone intravaginal insert to a timed insemination protocol using estradiol cypionate on ovulation rate, pregnancy rate, and late embryonic loss in lactating dairy cows. J. Anim. Sci. 82:3508-3517.

Gümen, A., J. N. Guenther, and M. C. Wiltbank. 2003. Follicular size and response to Ovsynch versus detection of estrus in anovular and ovular lactating dairy cows. J. Dairy Sci. 86:3184-3194.

Lamb, G. C., J. S. Stevenson, D. J. Kesler, H. A. Garverick, D. R. Brown, and B. E. Salfen. 2001. Inclusion of an intravaginal progesterone insert plus GnRH and prostaglandin F2 alpha for ovulation control in postpartum suckled beef cows. J. Anim. Sci. 79:2253-2259.

Lamming, G. E., and A. O. Darwash. 1998. The use of milk progesterone profiles to characterise components of subfertility in milked dairy cows. Anim. Reprod. Sci. 52:175-190.

LIC (Livestock Improvement Corp.) and DairyNZ. 2008. New Zealand dairy statistics 2007-08. http://www.dairynz.co.nz/dairystatistics Accessed Dec. 11, 2009.

Macmillan, K. L. 2002. Advances in bovine theriogenology in New Zealand. 1. Pregnancy, parturition and the postpartum period. N. Z. Vet. J. 50:67-73.

McDougall, S., C. R. Burke, K. L. Macmillan, and N. B. Williamson. 1992. The effect of pretreatment with progesterone on the oestrous 
response to oestradiol- $17 \beta$ benzoate in the post-partum dairy cow. N. Z. Soc. Anim. Prod. 52:157-160.

McDougall, S., and C. W. R. Compton. 2005. Reproductive performance of anestrous dairy cows treated with progesterone and estradiol benzoate. J. Dairy Sci. 88:2388-2400.

McDougall, S., and C. W. R. Compton. 2006. Reproductive performance in the subsequent lactation of dairy cows previously treated for failure to be detected in oestrus. N. Z. Vet. J. 54:132-140.

McDougall, S., and F. M. Rhodes. 1999. Detection of a corpus luteum in apparently anoestrous cows by manual palpation, transrectal ultrasonography and plasma progesterone concentrations. N. Z Vet. J. $47: 47-52$

McNutt, L. 2003. Estimating the relative risk in cohort studies and clinical trials of common outcomes. Am. J. Epidemiol. 157:940943.

Melendez, P., G. Gonzalez, E. Aguilar, O. Loera, C. Risco, and L. F. Archbald. 2006. Comparison of two estrus-synchronization protocols and timed artificial insemination in dairy cattle. J. Dairy Sci. 89:4567-4572.

Mihm, M. A. Baguisi, M. P. Boland, and J. F. Roche. 1994. Association between the duration of dominance of the ovulatory follicle and pregnancy rate in beef heifers. J. Reprod. Fertil. 102:123-130.

Opsomer, G., M. Coryn, H. Deluyker, and A. der Kruif. 1998. An analysis of ovarian dysfunction in high yielding dairy cows after calving based on progesterone profiles. Reprod. Domest. Anim. 33:193-204.

Peduzzi, P., W. Henderson, P. Hartigan, and P. Lavori. 2002. Analysis of randomized controlled trials. Epidemiol. Rev. 24:26-38.

Portaluppi, M. A., and J. S. Stevenson. 2005. Pregnancy rates in lactating dairy cows after presynchronization of estrous cycles and variations of the ovsynch protocol. J. Dairy Sci. 88:914-921.

Pursley, J. R., M. O. Mee, and M. C. Wiltbank. 1995. Synchronization of ovulation in dairy cows using $\mathrm{PGF}_{2 \alpha}$ and GnRH. Theriogenology 44:915-923.

Rhodes, F. M., S. McDougall, C. R. Burke, G. A. Verkerk, and K. L. Macmillan. 2003. Treatment of cows with an extended postpartum anestrous interval. J. Dairy Sci. 86:1876-1894.

Roche, J. F., E. J. Austin, M. Ryan, M. O'Rourke, M. Mihm, and M. G. Diskin. 1999. Regulation of follicle waves to maximize fertility in cattle. J. Reprod. Fertil. Suppl. 4:61-71.

Roche, J. R., P. G. Dillon, C. R. Stockdale, L. H. Baumgard, and M. J. VanBaale. 2004. Relationships among international body condition scoring systems. J. Dairy Sci. 87:3076-3079.

Santos, J. E. P., S. O. Juchem, R. L. A. Cerri, K. N. Galvão, R. C. Chebel, W. W. Thatcher, C. S. Dei, and C. R. Bilby. 2004. Effect of bST and reproductive management on reproductive performance of Holstein dairy cows. J. Dairy Sci. 87:868-881.

Savio, J. D., W. W. Thatcher, L. Badinga, R. L. de la Sota, and D. Wolfenson. 1993. Regulation of dominant follicle turnover during the oestrous cycle in cows. J. Reprod. Fertil. 97:197-203.
Sheffel, C. E., B. R. Pratt, W. L. Ferrell, and E. K. Inskeep. 1982. Induced corpora lutea in the postpartum beef cow. 2. Effects of treatment with progestogen and gonadotropins. J. Anim. Sci. $54: 830-836$.

Silva, E., R. A. Sterry, and P. M. Fricke. 2007. Assessment of a practical method for identifying anovular dairy cows synchronized for first postpartum timed artificial insemination. J. Dairy Sci. 90:3255-3262.

Sirois, J., and J. E. Fortune. 1990. Lengthening the bovine estrous cycle with low levels of exogenous progesterone: A model for studying ovarian follicular dominance. Endocrinology 127:916-925.

Souza, A. H., S. Viechnieski, F. A. Lima, F. F. Silva, R. Araújo, G. A. Bó, M. C. Wiltbank, and P. S. Baruselli. 2009. Effects of equine chorionic gonadotropin and type of ovulatory stimulus in a timed-AI protocol on reproductive responses in dairy cows. Theriogenology 72:10-21.

Sterry, R., P. Jardon, and P. Fricke. 2007. Effect of timing of Cosynch on fertility of lactating Holstein cows after first postpartum and resynch timed-AI services. Theriogenology 67:1211-1216.

Stevenson, J. S., Y. Kobayashi, M. P. Shipa, and K. C. Rauchholz. 1996. Altering conception of dairy cattle by gonadotropin-releasing hormone preceding luteolysis induced by prostaglandin $\mathrm{F}_{2 \alpha}$. J. Dairy Sci. 79:402-410.

Stevenson, J. S., Y. Kobayashi, and K. E. Thompson. 1999. Reproductive performance of dairy cows in various programmed breeding systems including OvSynch and combinations of gonadotropin-releasing hormone and prostaglandin $\mathrm{F}_{2 \alpha}$. J. Dairy Sci. 82:505-515.

Stevenson, J. S., J. R. Pursley, H. A. Garverick, P. M. Fricke, D. J. Kesler, J. S. Ottobre, and M. C. Wiltbank. 2006. Treatment of cycling and noncycling lactating dairy cows with progesterone during Ovsynch. J. Dairy Sci. 89:2567-2578.

Stevenson, J. S., D. E. Tenhouse, R. L. Krisher, G. C. Lamb, J. E. Larson, C. R. Dahlen, J. R. Pursley, N. M. Bello, P. M. Fricke, M. C. Wiltbank, D. J. Brusveen, M. Burkhart, R. S. Youngquist, and H. A. Garverick. 2008. Detection of anovulation by heatmount detectors and transrectal ultrasonography before treatment with progesterone in a timed insemination protocol. J. Dairy Sci 91:2901-2915.

Twagiramungu, H., L. A. Guilbault, and J. J. Dufour. 1995. Synchronization of ovarian follicular waves with a gonadotropinreleasing hormone agonist to increase the precision of estrus in cattle: A review. J. Anim. Sci. 73:3141-3151.

Webb, R., G. E. Lamming, N. B. Haynes, and G. R. Foxcroft. 1980. Plasma progesterone and gonadotrophin concentrations and ovarian activity in post-partum dairy cows. J. Reprod. Fertil. $59: 133-143$ 